ISSN = 1980-993X - doi:10.4136/1980-993X
www.ambi-agua.net
E-mail: ambi-agua@agro.unitau.br
Tel.: (12) 3625-4212

\title{
Desempenho de sistema decanto-digestor com filtro biológico seguido por alagado construído e reator solar no tratamento de esgoto doméstico
}

\author{
(http://dx.doi.org/10.4136/ambi-agua.723)
}

Glícia Pinto Barra Reinaldo'; Rafael Oliveira Batista ${ }^{1}$; Paulo Cesar Moura da Silva1; Luis Cesar de Aquino Lemos Filho ${ }^{1}$; Miguel Ferreira Neto ${ }^{1}$; Delfran Batista dos Santos ${ }^{2}$

\author{
${ }^{1}$ Universidade Federal Rural do Semi-Árido - UFERSA, Mossoró-RN, \\ e-mails: gliciapinto@gmail.com,rafaelbatista@ufersa.edu.br,paulo.moura@ufersa.edu.br, \\ lcalfilho@ufersa.edu.br, miguel@ufersa.edu.br, \\ ${ }^{2}$ Instituto Federal de Educação, Ciência e Tecnologia Baiano, Senhor do Bonfim-BA, \\ e-mail: delfran.batista@gmail.com
}

\section{RESUMO}

O presente trabalho objetivou analisar o desempenho de sistema decanto-digestor com filtro biológico seguido por alagado construído e reator solar no tratamento de esgoto doméstico do assentamento rural Milagres em Apodi-RN. Nos meses de outubro e novembro de 2010 realizou-se o monitoramento do sistema 48 dias após o plantio do capim elefante (Pennisetum purpureum Schumach). Foram coletadas amostras do esgoto doméstico nas distintas etapas de tratamento, em quatro repetições no tempo, para determinação de características físico-químicas e microbiológicas referentes ao desempenho do sistema. Os resultados indicaram que houve remoção significativa de turbidez, Demanda Bioquímica de Oxigênio, Demanda Química de Oxigênio, sólidos totais, sólidos suspensos, fósforo e óleos e graxas com o uso sistema decanto-digestor com filtros biológicos seguidos de alagado construído e reator solar; a associação de radiação solar média de $28,73 \mathrm{MJ} \mathrm{m}^{-2} \mathrm{~d}^{-1}$, lâmina de 0,10 m de efluente no reator e tempo de exposição solar de 12 horas permitiu remoção de até 99,99\% dos coliformes termotolerantes no esgoto doméstico em Apodi-RN; e o efluente tratado apresenta padrão microbiológico satisfatório às diretrizes brasileiras para uso agrícola com restrição.

Palavras-chave: sustentabilidade, saneamento básico, água residuária.

\section{Performance of digester decant system with biological filter followed by constructed wetland and solar reactor in the treatment of domestic sewage}

\begin{abstract}
This study aimed to analyze the performance of digester decant system with biological filter followed by constructed wetland and solar reactor in the treatment of domestic sewage from Milagres rural community in Apodi-RN. The treatment system was monitored for the period of October and November 2010, 48 days after planting Pennisetum purpureum Schumach. Samples of domestic sewage were collected at different stages of treatment, in four replications on time, to determine physicochemical and microbiological characteristics about the system performance. The results indicated significant removal of turbidity, biochemical oxygen demand, chemical oxygen demand, total solids, suspended solids,
\end{abstract}


REINALDO, G. P. B.; BATISTA, R. O.; SILVA, P. C. M.; LEMOS FILHO, L. C. A.; FERREIRA NETO, M. SANTOS, D. B. Desempenho de sistema decanto-digestor com filtro biológico seguido por alagado construído e reator solar no tratamento de esgoto doméstico. Ambi-Agua, Taubaté, v. 7, n. 2, p. 62-74, 2012. (http://dx.doi.org/10.4136/ambi-agua.723)

phosphorus and oil and grease using the set digester decant with biological filter, followed by constructed wetland and solar reactor; the association of average solar radiation of $28.73 \mathrm{MJ} \mathrm{m}^{-2} \mathrm{~d}^{-1}$, effluent depth of $0.10 \mathrm{~m}$ on reactor and time of sun exposure of 12 hours provided removal of fecal coliform up to $99.99 \%$ of domestic sewage in Apodi, RN, the treated effluent met microbiological standard of the Brazilian guidelines for agricultural use with restrictions.

Keywords: sustainability, sanitation, wastewater.

\section{INTRODUÇÃO}

A inadequação dos serviços de saneamento básico é a principal causa de doenças e de poluição ambiental no mundo. De acordo com o HDR (UNDP, 2006), cerca de 2,6 bilhões de habitantes moram em domicílio sem rede de esgoto. Em detrimento disso, anualmente, cerca de 1,7 milhões de crianças morrem em resultado direto de diarréia e de outras doenças provocadas por água contaminada e por más condições de saneamento.

Segundo a Pesquisa Nacional de Saneamento Básico de 2008, 44,8\% dos municípios brasileiros não possuíam rede coletora de esgoto. Enquanto, apenas $28,5 \%$ desses municípios dispõem de sistema para tratamento de esgoto (IBGE, 2010).

No que concerne às companhias de saneamento, o lançamento de esgoto doméstico bruto em corpos hídricos altera as características naturais da água, a partir do ponto de lançamento e compromete sua qualidade para consumo humano ou mesmo para uso em atividades agropecuárias e agroindustriais (Ribas e Fortes Neto, 2008).

Atualmente, as tecnologias utilizadas pelas companhias de saneamento tornam-se inviáveis para comunidades rurais de baixa renda de regiões semiáridas, tanto pelo alto custo de implantação e manutenção quanto pela grande dispersão populacional nas zonas rurais (Batista et al., 2011). Portanto, é necessário o desenvolvimento de tecnologias de baixo custo e de fácil operação para o tratamento de esgoto doméstico; e que possibilite aumento de renda pelo uso do efluente tratado na irrigação de cultivos agrícolas. Nesse sentido, destacam-se as seguintes tecnologias:

1. Tanque séptico: este dispositivo visa à retenção de sólidos flutuantes; decantação de sólidos sedimentáveis; alteração das características da fase líquida; deposição acúmulo e adensamento do lodo decantado em regime de decomposição anaeróbia; digestão parcial da escuma; redução sensível do número de bactérias patogênicas. Este é recomendado para o tratamento de esgotos gerados por até 300 pessoas, removendo em média 50\% da Demanda Bioquímica de Oxigênio (Matos, 2007).

2. Filtro anaeróbio: este dispositivo proporciona tratamento físico (filtração) e biológico (anaeróbio), complementar ao obtido no tanque séptico, removendo até $85 \%$ da Demanda Bioquímica de Oxigênio (Matos, 2007).

3. Sistema alagado construído (SACs): este dispositivo é construído em alvenaria ou com manta impermeabilizante preenchidos internamente com material poroso e inerte (cascalho, brita, tampa de garrafa pet e outros). Sobre o meio filtrante é cultivada espécies de plantas com grande capacidade de extração de poluentes presentes nos esgotos domésticos. Para evitar o surgimento de odores desagradáveis, insetos e animais peçonhentos, recomenda-se a utilização de fluxo subsuperficial do esgoto doméstico (Matos, 2007). Prochaska e Zoubouslis (2008) observaram remoções de 52, 60 e 96\% nas concentrações de fósforo total, nitrato e Demanda Química de Oxigênio em SAC abastecido com esgoto doméstico, tendo o junco (phragmites australis) como planta extratora. Brasil et al. (2005) trabalharam com taboa (Typha sp) com dois diferentes tempos de residência hidráulica e quatro tipos de SACs no 
tratamento de efluente doméstico proveniente de tanque séptico, obtendo ao final dos ensaios experimentais redução média nos valores de Demanda Química de Oxigênio, sólidos suspensos, turbidez, nitrogênio total e fósforo total de $87,91,88,33$ e $35 \%$, respectivamente.

4. Reatores solares: são tanques construídos em alvenaria ou fibra de vidro que possibilitam o armazenamento de esgoto doméstico para exposição direta à radiação solar local, visando à inativação dos microrganismos patogênicos. A Região Nordeste se apresenta como a mais promissora para a aplicação desta tecnologia. Nos estados do Piauí e Maranhão, durante o ano todo, é preciso dois dias de exposição solar, em profundidade (até 0,20 m) da água residuária a ser tratada. Nas Regiões Sudeste e Centro Oeste, durante o inverno, são necessários menos de 2,5 dias; enquanto, no resto do ano serão necessários dois dias de exposição solar (Sánchez-Román et al., 2007).

O presente trabalho objetivou avaliar o desempenho de sistema decanto-digestor com filtro biológico seguido por alagado construído e reator solar no tratamento de esgoto doméstico do assentamento rural Milagres em Apodi-RN.

\section{MATERIAIS E MÉTODO}

O presente trabalho foi realizado no Projeto de Assentamento Rural Milagres em ApodiRN, situado a $100 \mathrm{~km}$ de Mossoró-RN, sob as coordenadas geográficas 5³5’22” de latitude sul e 3754'09" de longitude oeste.

O assentamento Milagres possui 107 habitantes em 28 residências e dispõe de rede coletora de todo esgoto doméstico produzido, além de um decanto-digestor para tratamento preliminar e primário do esgoto doméstico bruto. Tal sistema possui um tanque séptico com duas câmaras, gradeamento e dois filtros anaeróbios de fluxo descendente. O decanto-digestor foi dimensionado para tratar uma vazão ate $20 \mathrm{~m}^{3} \mathrm{~d}^{-1}$ de esgoto doméstico com remoção do lodo a cada dois anos. No período experimental de setembro a dezembro de 2010 a vazão no sistema era de $12 \mathrm{~m}^{3} \mathrm{~d}^{-1}$, tendo em vista que apenas 60 pessoas estavam gerando esgoto doméstico.

Ao lado do decanto-digestor foi implantado um sistema alagado construído e um reator solar para tratamento secundário e terciário do esgoto doméstico. Na Figura 1 está apresentada a sequência do tratamento de esgoto no assentamento Milagres em Apodi-RN.

Decanto-digestor com filtros biológicos: objetiva a remoção de sólidos suspensos decantáveis, areia e óleos e graxas, efetuando o tratamento preliminar/primário. Este dispositivo foi construído em alvenaria de tijolos e reboco com impermeabilizante, nas dimensões de 4,0 m de largura por 8,0 m de comprimento por 1,80 $\mathrm{m}$ de profundidade (Figura 1b). No entanto, a profundidade útil do sistema foi de $1,30 \mathrm{~m}$, além de ser dividido da seguinte forma: a) um tanque séptico com duas câmaras, medindo de 2,0 $\mathrm{m}$ de largura por 7,6 $\mathrm{m}$ de comprimento por $1,30 \mathrm{~m}$ de profundidade útil, tempo de detenção hidráulica de 0,5 dia, frequência para remoção do lodo a cada dois anos, ocupando um volume de cerca de $21 \mathrm{~m} 3$; b) grade tipo fina para remoção de material particulado com tamanho de até 0,02 $\mathrm{m}$ nas dimensões de 1,0 m de largura por 2,0 m de comprimento, instalada a jusante do tanque séptico; e c) dois filtros anaeróbios de fluxo descendente, cada uma nas dimensões de 1,0 m de largura por $6,0 \mathrm{~m}$ de comprimento por $1,30 \mathrm{~m}$ de profundidade útil, ocupando os dois um volume de 16,0 m3. Os filtros anaeróbios foram preenchidos, internamente, com tijolos cerâmicos de oito furos para auxiliar na formação de biofilme para degradação de poluentes químicos e orgânicos presentes no efluente. $\mathrm{O}$ tempo de detenção hidráulica estimado para cada filtro é aproximadamente de duas horas. Foi dimensionamento conforme as recomendações da NBR 7229 (ABNT, 1993). 
REINALDO, G. P. B.; BATISTA, R. O.; SILVA, P. C. M.; LEMOS FILHO, L. C. A.; FERREIRA NETO, M. SANTOS, D. B. Desempenho de sistema decanto-digestor com filtro biológico seguido por alagado construído e reator solar no tratamento de esgoto doméstico. Ambi-Agua, Taubaté, v. 7, n. 2, p. 62-74, 2012. (http://dx.doi.org/10.4136/ambi-agua.723)

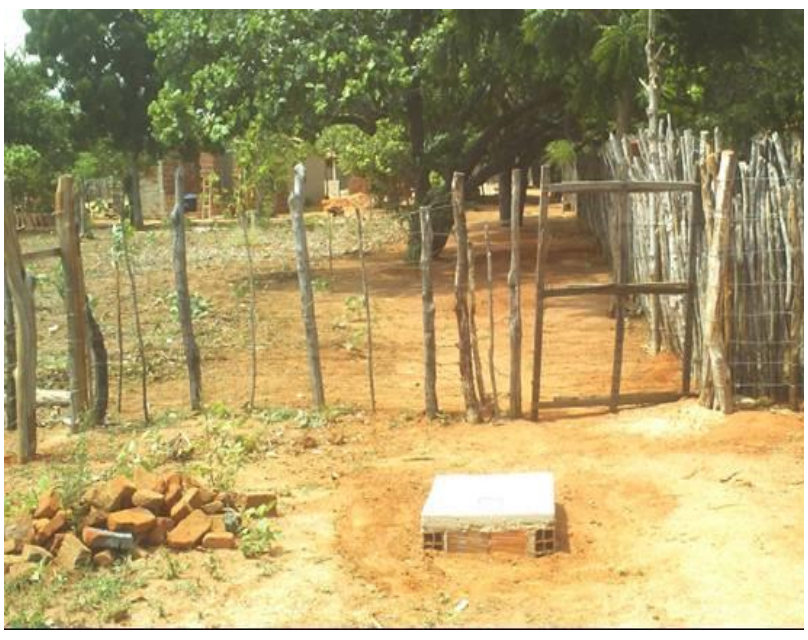

(a)

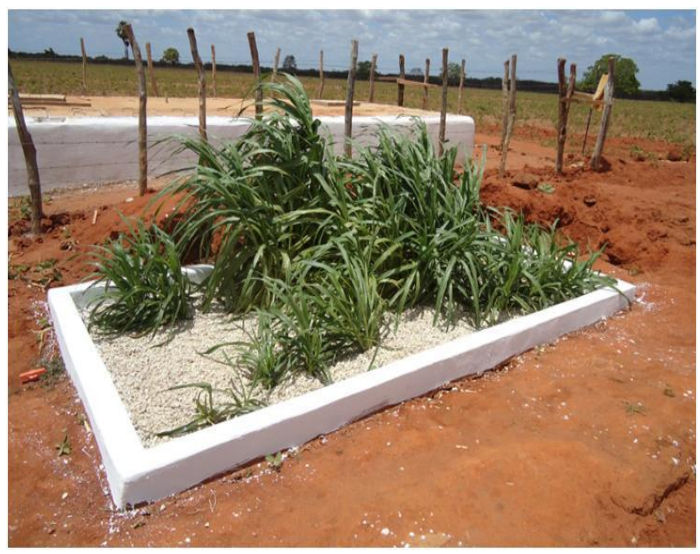

(c)

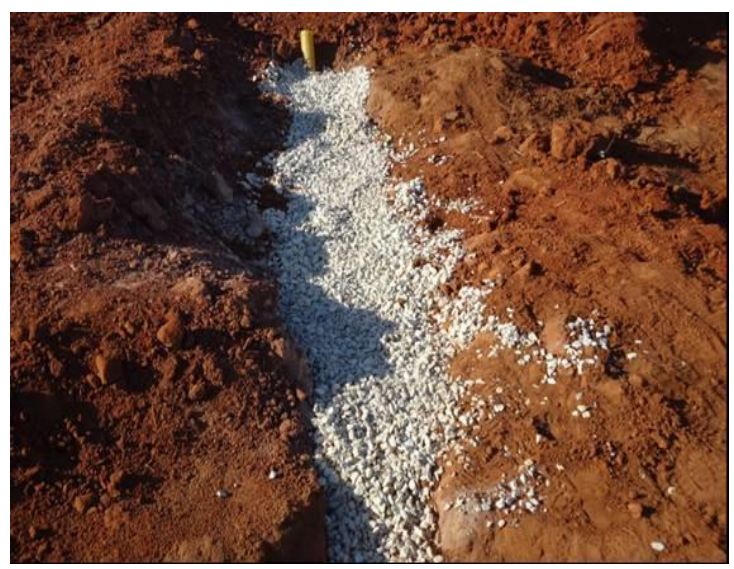

(e)

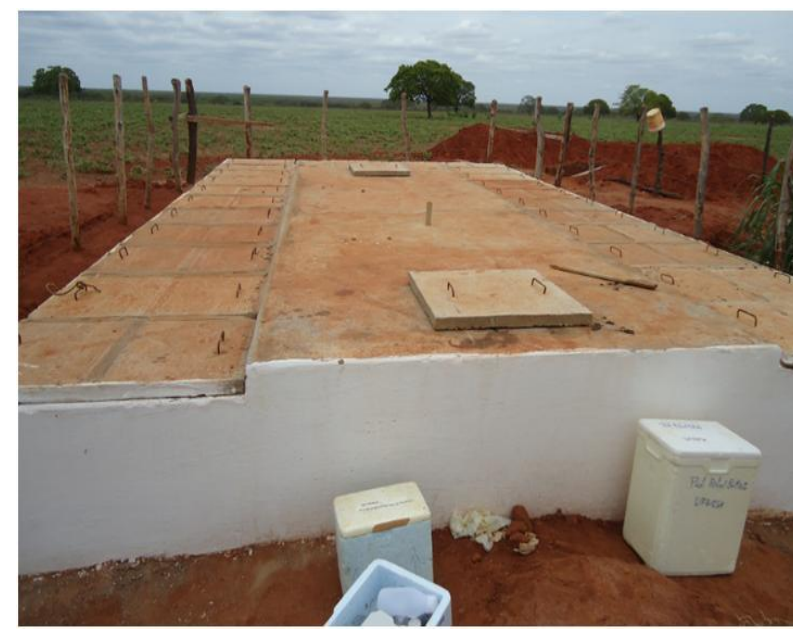

(b)

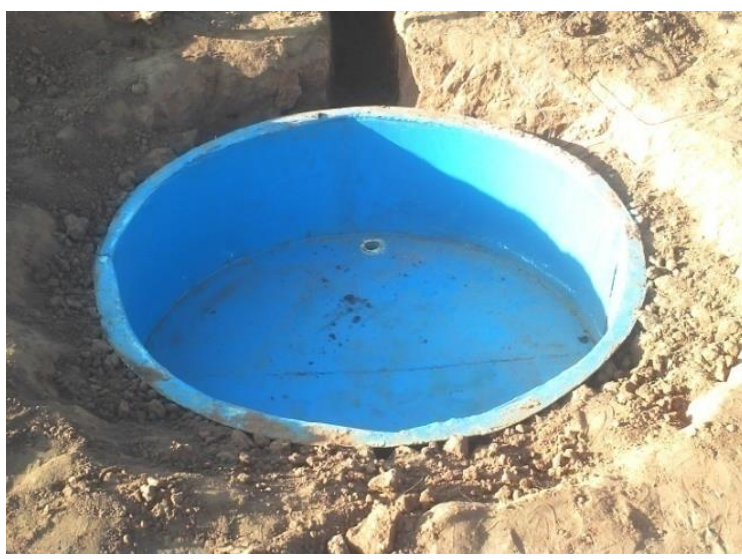

(d)

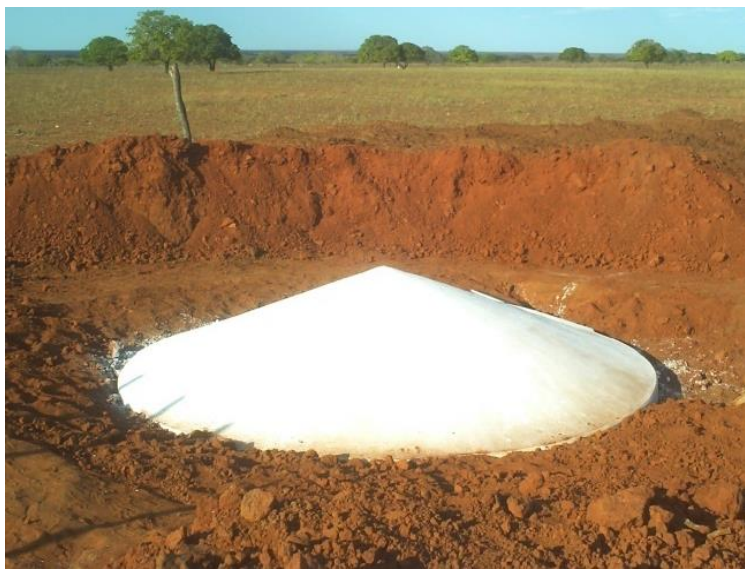

(f)

Figura 1. Sequência do sistema de tratamento e aproveitamento esgoto doméstico implantado no assentamento Milagres, área experimental da UFERSA, em Apodi-RN. Detalhe das caixas de passagem (a), decanto-digestor (b), mini-sistema alagado construído (c), reator solar (d), sumidouro (e) e reservatório para efluente tratado visando a irrigação (f). 
REINALDO, G. P. B.; BATISTA, R. O.; SILVA, P. C. M.; LEMOS FILHO, L. C. A.; FERREIRA NETO, M. SANTOS, D. B. Desempenho de sistema decanto-digestor com filtro biológico seguido por alagado construído e reator solar no tratamento de esgoto doméstico. Ambi-Agua, Taubaté, v. 7, n. 2, p. 62-74, 2012. (http://dx.doi.org/10.4136/ambi-agua.723)

Sistema alagado construído: composto por um leito com fluxo subsuperficial horizontal, para tratamento secundário/terciário do esgoto doméstico, construído em alvenaria nas dimensões de 2,0 $\mathrm{m}$ de largura por 4,0 $\mathrm{m}$ de comprimento por $0,50 \mathrm{~m}$ de profundidade, enterrado no solo. O meio suporte utilizado foi a brita 1 que possibilitará a formação do biofilme para o tratamento biológico do efluente (Figura 1c). No dia 23 de setembro de 2010 foram plantadas os colmos de capim elefante (Pennisetum purpureum Schumach) no sistema alagado construído no espaçamento de $0,60 \mathrm{~m}$ entre fileiras e $0,60 \mathrm{~m}$ entre centro de colmos. Tal espécie vegetal foi escolhida por capacidade de extração de nutrientes da água residuária e posterior conversão em biomassa (Oliveira et al., 2008) que pode, após exposição à radiação solar, servir como alimento para pequenas criações de animais no assentamento (bovinos, caprinos e ovinos). No dimensionamento do sistema alagado construído foi considerada uma vazão de $1,0 \mathrm{~m}^{3} \mathrm{~d}^{-1}$, taxa de aplicação de $400 \mathrm{~kg}$ de DBO ha-1 $\mathrm{d}^{-1}$ e concentração típica de DBO do esgoto doméstico de $300 \mathrm{mg} \mathrm{L}^{-1}$ seguindo as recomendações de Matos (2007).

Reator solar: este possibilita a redução do nível populacional dos coliformes termotolerantes, sendo denominado tratamento terciário. Tal dispositivo foi construído em fibra de vidro $(3 \mathrm{~mm})$, no formato cilíndrico, conforme as recomendações de Sánchez-Román et al. (2007) nas dimensões de $1,30 \mathrm{~m}$ de diâmetro e $0,40 \mathrm{~m}$ de profundidade, dotado de capacidade máxima armazenadora para $0,53 \mathrm{~m}^{3}$ (Figura 1d). No interior do reator foi fixada uma régua com precisão de um centímetro para o monitoramento da lâmina de efluente a ser tratado. Este dispositivo foi operado com uma lâmina de efluente de $0,10 \mathrm{~m}$ durante um período de exposição à radiação solar de 12 horas, de acordo com Moura et al. (2011).

Sumidouro: este dispositivo, também, permite o tratamento secundário e terciário do esgoto doméstico. O sumidouro só foi utilizado para infiltrar o volume de esgoto doméstico tratado no reator solar, ou seja, cerca de $0,13 \mathrm{~m}^{3}$ a cada ensaio realizado (Figura 1e). O restante do volume de esgoto doméstico tratado pelo sistema alagado construído era lançado em um reservatório para posterior aproveitamento na agricultura. Com um ensaio prévio de infiltração constatou-se que o coeficiente de infiltração do solo na área foi de $65 \mathrm{~L} \mathrm{~m}^{-2} \mathrm{~d}^{-1}$. No dimensionamento do sumidouro foram levadas em consideração as recomendações NBR 7229 (ABNT, 1982);

Reservatório: este dispositivo permite armazenar o efluente tratado no sistema alagado construído que não foi destinado ao sumidouro para a irrigação de cultivo agrícolas no Assentamento Milagres. Construído em concreto armado com capacidade armazenadora para $10 \mathrm{~m}^{3}$, tendo diâmetro de 3,5 m e profundidade de 1,0 m (Figura 1f).

No período de 20 de outubro a 10 de novembro de 2010 foram realizadas quatro amostragens de efluentes nos seguintes pontos do sistema: Ponto 1 - efluente coletado na entrada do decanto-digestor; Ponto 2 - efluente coletado na saída do decanto-digestor; Ponto 3 - efluente coletado à jusante do sistema alagado construído; e Ponto 4 - efluente coletado no reator solar.

Para caracterização físico-química dos efluentes, amostras foram coletadas nos pontos 1 , 2, 3 e 4 do sistema e preservadas em caixas isotérmicas com gelo à temperatura de $4^{\circ} \mathrm{C}$ até a entrada no laboratório, conforme recomendações do Standard methods for the examination of water and wastewater (APHA, 2005). Posteriormente, tais amostras foram encaminhadas para o Laboratório de Diagnóstico Físico-Químico da Universidade Estadual do Rio Grande do Norte (UERN) onde foram realizadas análises de: $\mathrm{pH}$ (método eletrométrico utilizando medidor de bancada), condutividade elétrica (condutivímetro de bancada), turbidez (turbidímetro de bancada), Demanda Química de Oxigênio (método oxidimétrico com refluxo), Demanda Bioquímica de Oxigênio (método iodométrico pelo processo Winkler), sólidos totais (método gravimétrico), sólidos suspensos (método gravimétrico com a utilização de membranas de fibra de vidro com $0,45 \mu \mathrm{m}$ de diâmetro de poro), nitrogênio total 
REINALDO, G. P. B.; BATISTA, R. O.; SILVA, P. C. M.; LEMOS FILHO, L. C. A.; FERREIRA NETO, M. SANTOS, D. B. Desempenho de sistema decanto-digestor com filtro biológico seguido por alagado construído e reator solar no tratamento de esgoto doméstico. Ambi-Agua, Taubaté, v. 7, n. 2, p. 62-74, 2012. (http://dx.doi.org/10.4136/ambi-agua.723)

(pelo método Kjeldhal), fósforo total (espectrofotometria), óleos e graxas (extrator Soxhlet) e nitrato (espectrofotometria), conforme recomendações do Standard methods for the examination of water and wastewater (APHA, 2005).

Para caracterização microbiológica dos efluentes, amostras foram coletadas em frasco esterilizados nos pontos 1 e 4 do sistema às 14:00 horas. Estas amostras foram preservadas em caixa isotérmica com gelo, foram encaminhadas para o Laboratório de Inspeção de Produtos de Origem Animal, localizado na Universidade Federal Rural do Semiárido (UFERSA) para identificação e quantificação dos níveis populacionais de coliformes totais e coliformes termotolerantes (método de tubos múltiplos), conforme recomendações do Standard methods for the examination of water and wastewater (APHA, 2005). Deve-se ressaltar que para avaliar estas características foi necessário o preparo do reator solar, um dia antes da amostragem, ou seja, às 14:00 horas do dia anterior armazenava-se uma lâmina de efluente no reator de cerca de $0,10 \mathrm{~m}$, para exposição à radiação solar local, e posterior coleta no dia seguinte.

No período de 11 a 17 de setembro de 2011, foi realizada a medição da vazão que estava passando pelo sistema alagado construído. Para tal, foi utilizado o método gravimétrico. $\mathrm{O}$ volume médio semanal de esgoto foi de 1932 L, resultando em uma vazão média de $80,51 \mathrm{~L} \mathrm{~h}^{-1}$.

Nos pontos 1 e 4 foram analisadas todas as variáveis, enquanto que nos pontos 2 e 3 foram analisados somente $\mathrm{pH}$, condutividade elétrica. turbidez, sólidos totais e sólidos suspensos. Os dados de radiação solar, por sua vez, foram obtidos junto ao Instituto Nacional de Meteorologia (INMET) para o período de avaliação da pesquisa. Deve-se ressaltar, também, que foi realizado um registro fotográfico do esgoto coletado nos pontos 1 e 4 para comparação visual do tratamento proporcionado.

O experimento foi montado no delineamento inteiramente casualizado (DIC) com quatro repetições no tempo. Como as variáveis são qualitativas, optou-se pela seguinte procedimento de análise estatística: a) os dados foram, inicialmente, submetidos a analise de variância, utilizando-se o teste $\mathrm{F}$ com significância de até 5\%; e b) as médias foram comparadas empregando-se o teste de Tukey com significância de até 5\%. O programa computacional SAEG 9.1 foi utilizado na análise estatística.

\section{RESULTADOS E DISCUSSÃO}

Na Tabela 1 estão apresentados os valores integralizados de radiação global no período de monitoramento do sistema de tratamento de esgoto. A radiação solar oscilou de 24,45 a $31,48 \mathrm{MJ} \mathrm{m}^{-2} \mathrm{~d}^{-1}$ no período experimental, tendo o valor médio de $28,73 \mathrm{MJ} \mathrm{m}^{-2} \mathrm{~d}^{-1}$.

$\mathrm{Na}$ Tabela 2 estão apresentados os resultados das análises físicas, químicas e microbiológicas dos efluentes coletados nos protótipos de tratamento de esgoto doméstico, no período de 20 de outubro a 10 de novembro de 2010, no Assentamento Milagres em ApodiRN.

Tabela 1. Valores integralizados de radiação global no período de monitoramento do sistema de tratamento de esgoto.

\begin{tabular}{c|c}
\hline Data & Radiação acumulada $\left(\mathbf{M J ~ m}^{-\mathbf{2}} \mathbf{d}^{-\mathbf{1}}\right)$ \\
\hline 19/10 a 20/10 & 27,90 \\
26/10 a 27/10 & 24,45 \\
02/10 a 03/11 & 31,48 \\
09/11 a 10/11 & 31,08 \\
\hline Média & $\mathbf{2 8 , 7 3}$ \\
\hline
\end{tabular}


REINALDO, G. P. B.; BATISTA, R. O.; SILVA, P. C. M.; LEMOS FILHO, L. C. A.; FERREIRA NETO, M. SANTOS, D. B. Desempenho de sistema decanto-digestor com filtro biológico seguido por alagado construído e reator solar no tratamento de esgoto doméstico. Ambi-Agua, Taubaté, v. 7, n. 2, p. 62-74, 2012. (http://dx.doi.org/10.4136/ambi-agua.723)

Tabela 2. Características físicas, químicas e microbiológicas dos efluentes coletados na mini-estação de tratamento de esgoto doméstico ao longo do período experimental.

\begin{tabular}{|c|c|c|c|c|c|c|c|c|c|c|c|c|c|}
\hline \multirow[t]{2}{*}{ Pontos } & pH & $\mathbf{C E}$ & TB & CT & CTe & DQO & DBO & ST & SS & $\mathbf{P}_{\text {total }}$ & $\mathbf{N}_{\text {total }}$ & OG & $\mathrm{NO}_{3}{ }^{-}$ \\
\hline & & dS $\mathbf{m}^{-1}$ & UNT & NM & $\mathbf{m L}$ & \multicolumn{8}{|c|}{$m g L^{-1}$} \\
\hline
\end{tabular}

Amostragem de 20 de outubro de 2010

\begin{tabular}{|c|c|c|c|c|c|c|c|c|c|c|c|c|c|}
\hline Ponto 1 & 5,78 & 1,32 & 971,00 & $1,1 \times 10^{7}$ & $1,1 \times 10^{5}$ & 455,67 & 165,24 & 946 & 592 & 25,79 & 59,15 & 357,20 & 11,11 \\
\hline Ponto 2 & 6,02 & 1,31 & 189,00 & & & & & 618 & 234 & & & & \\
\hline Ponto 3 & 6,50 & 1,30 & 58,00 & & & & & 385 & 64 & & & & \\
\hline Ponto 4 & 6,56 & 1,29 & 45,00 & $3,0 \times 10^{2}$ & $3,0 \times 10^{1}$ & 121,15 & 71,40 & 372 & 68 & 14,26 & 55,31 & 1,02 & 5,86 \\
\hline $\mathbf{M}$ & 6,215 & 1,30 & 315,75 & $5,9 \times 10^{4 *}$ & $1,8 \times 10^{3^{*}}$ & 288,41 & 118,32 & 581 & 240 & 20,025 & 57,23 & 179,11 & 8,49 \\
\hline DP & 0,38 & $\mathbf{0 , 0 1}$ & 441,65 & $1,6 \times 10^{3 *}$ & $3,3 \times 10^{2 *}$ & 236,54 & 66,35 & 268,76 & 247,99 & 8,15 & 2,72 & 251,86 & 3,71 \\
\hline
\end{tabular}

Amostragem de 27 de outubro de 2010

\begin{tabular}{|c|c|c|c|c|c|c|c|c|c|c|c|c|c|}
\hline Ponto 1 & 6,12 & 0,97 & 556,50 & $6,0 \times 10^{8}$ & $5,4 \times 10^{6}$ & 500,20 & 180,40 & 934 & 390 & 25,70 & 49,16 & 169,50 & 23,18 \\
\hline Ponto 2 & 6,23 & 1,03 & 69,61 & & & & & 676 & 262 & & & & \\
\hline Ponto 3 & 6,55 & 1,05 & 8,98 & & & & & 646 & 40 & & & & \\
\hline Ponto 4 & 6,18 & 1,03 & 9,61 & $5,0 \times 10^{4}$ & $4,0 \times 10^{2}$ & 132,50 & 78,30 & 610 & 16 & 15,26 & 55,32 & 3,10 & 42,52 \\
\hline $\mathbf{M}$ & 6,27 & 1,02 & 161,175 & $5,5 \times 10^{6 *}$ & $5,7 \times 10^{4 *}$ & 316,35 & 129,35 & 717 & 177 & 20,48 & 52,24 & 86,30 & 32,85 \\
\hline DP & 0,19 & $\mathbf{0 , 0 3}$ & 265,08 & $7,3 \times 10^{2^{*}}$ & $8,3 \times 10^{2^{*}}$ & 260,00 & 72,20 & 147 & 180 & 7,38 & 4,36 & 117,66 & 13,68 \\
\hline
\end{tabular}

Amostragem de 03 de novembro de 2010

\begin{tabular}{l|ccccccccccccc}
\hline Ponto 1 & 6,28 & 1,28 & 478,30 & $1,1 \times 10^{7}$ & $7,4 \times 10^{5}$ & 390,50 & 180,40 & 915 & 400 & 27,64 & 57,18 & 158,20 & 9,26 \\
\hline Ponto 2 & 7,22 & 1,33 & 100,30 & & & & & 804 & 264 & & & \\
\hline Ponto 3 & 6,83 & 1,04 & 36,13 & & & & & 450 & 8 & & & \\
\hline Ponto 4 & 6,91 & 1,05 & 31,48 & $7,0 \times 10^{4}$ & $6,7 \times 10^{2}$ & 140,30 & 68,90 & 366 & 6 & 16,29 & 51,39 & 2,10 & 28,54 \\
\hline M & $\mathbf{6 , 8 1}$ & $\mathbf{1 , 1 7 5}$ & $\mathbf{1 6 1 , 5 5 5}$ & $\mathbf{8 , 8 \times 1 0 ^ { 5 * }}$ & $\mathbf{2 , 2 \times 1 0 ^ { 4 * }}$ & $\mathbf{2 6 5 , 4}$ & $\mathbf{1 2 4 , 6 5}$ & $\mathbf{6 3 4}$ & $\mathbf{1 7 0}$ & $\mathbf{2 1 , 9 6 5}$ & $\mathbf{5 4 , 2 8}$ & $\mathbf{8 0 , 1 5}$ & $\mathbf{1 8 , 9}$ \\
\hline DP & $\mathbf{0 , 3 9}$ & $\mathbf{0 , 1 5}$ & $\mathbf{2 1 3 , 4 9}$ & $\mathbf{3 , 6 x 1 0 ^ { * }}$ & $\mathbf{1 , 4 x 1 0}^{*}$ & $\mathbf{1 7 6 , 9 2}$ & $\mathbf{7 8 , 8 4}$ & $\mathbf{2 6 7}$ & $\mathbf{1 9 6}$ & $\mathbf{8 , 0 3}$ & $\mathbf{4 , 0 9}$ & $\mathbf{1 1 0 , 3 8}$ & $\mathbf{1 3 , 6 3}$ \\
\hline
\end{tabular}

Amostragem de 10 de novembro de 2010

\begin{tabular}{|c|c|c|c|c|c|c|c|c|c|c|c|c|c|}
\hline Ponto 1 & 6,50 & 1,35 & 300,20 & $3,0 \times 10^{8}$ & $3,1 \times 10^{6}$ & 490,40 & 200,20 & 895 & 310 & 17,40 & 58,28 & 148,20 & 10,60 \\
\hline Ponto 2 & 7,12 & 1,37 & 106,20 & & & & & 845 & 284 & & & & \\
\hline Ponto 3 & 6,72 & 1,39 & 45,30 & & & & & 470 & 11 & & & & \\
\hline Ponto 4 & 6,80 & 1,40 & 47,80 & $2,0 \times 10^{5}$ & $8,1 \times 10^{2}$ & 160,20 & 70,01 & 460 & 10 & 6,90 & 49,90 & 6,90 & 30,40 \\
\hline M & 6,785 & 1,38 & 124,85 & $7,8 \times 10^{6 *}$ & $5,0 \times 10^{4 *}$ & 325,30 & 135,10 & 667,5 & 154 & 12,15 & 54,09 & 77,55 & 20,5 \\
\hline DP & 0,26 & $\mathbf{0 , 0 2}$ & 120,22 & $1,8 \times 10^{2^{*}}$ & $3,4 \times 10^{2^{*}}$ & 233,49 & 92,06 & 234,5 & 166 & 7,42 & 5,93 & 99,91 & 14,00 \\
\hline
\end{tabular}

Nota: M - média; DP - desvio-padrão; Ponto 1: efluente coletado na entrada do decanto-digestor; Ponto 2: efluente coletado na saída do decanto-digestor; Ponto 3: efluente coletado à jusante do sistema alagado construído; e Ponto 4: efluente coletado no reator solar. pH - potencial hidrogeniônico; CE - condutividade elétrica; TB - turbidez; CT coliformes totais; CTe - coliformes termotolerantes; DQO - demanda química de oxigênio; DBO - demanda bioquímica de oxigênio; ST - sólidos totais; SS - sólidos suspensos; $\mathrm{P}_{\text {total }}$ - fósforo total; $\mathrm{N}_{\text {total }}$ - nitrogênio total; OG óleos e graxas; e $\mathrm{NO}_{3}{ }^{-}$- nitrato. * Média e desvio-padrão geométrico. 
REINALDO, G. P. B.; BATISTA, R. O.; SILVA, P. C. M.; LEMOS FILHO, L. C. A.; FERREIRA NETO, M. SANTOS, D. B. Desempenho de sistema decanto-digestor com filtro biológico seguido por alagado construído e reator solar no tratamento de esgoto doméstico. Ambi-Agua, Taubaté, v. 7, n. 2, p. 62-74, 2012. (http://dx.doi.org/10.4136/ambi-agua.723)

O tratamento proporcionado pelo sistema alterou as características físicas e químicas do esgoto doméstico. Constatou-se que, o valor de turbidez, Demanda Química de Oxigênio, Demanda Bioquímica de Oxigênio, sólidos suspensos, sólidos totais, fósforo e óleos e graxas reduziram a medida que o efluente passou pelas distintas etapas de tratamento. Enquanto, as características nitrogênio total e nitrato não foram removidas eficientemente, nesse período, pelo fato do capim elefante ainda estar na fase de desenvolvimento inicial (altura de 1,40 m) no sistema alagado construído. O ciclo do capim elefante é uma gramínea triploide com tempo de utilização de 110 dias fornecendo cortes da forragem a cada 50 dias. O sistema alagado construído melhorou muito a qualidade do esgoto no que se refere ao lançamento em corpo hídrico em função dos seguintes processos: a) remoção de nutrientes como nitrogênio, fósforo e nitrato pelo capim elefante; b) redução da Demanda Bioquímica de oxigênio e do nível populacional dos coliformes termotolerantes pelo biofilme formado no sistema; e c) remoção dos sólidos suspensos pela filtração do meio poroso e do sistema radicular do capim elefante. Os valores de $\mathrm{pH}$ e condutividade elétrica não apresentaram alterações, ao longo do período experimental (Tabela 2).

Estabelecendo comparação entre os valores de turbidez dos efluentes coletados nos pontos 1 e 4, nos quatro dias de amostragem, notaram-se remoções de 84 a $98 \%$. No ponto 4 , os valores de turbidez oscilaram de 45,0 a 47,8 UNT. Na Figura 2 está apresentada a variação encontrada na remoção de turbidez, ao longo do período experimental.

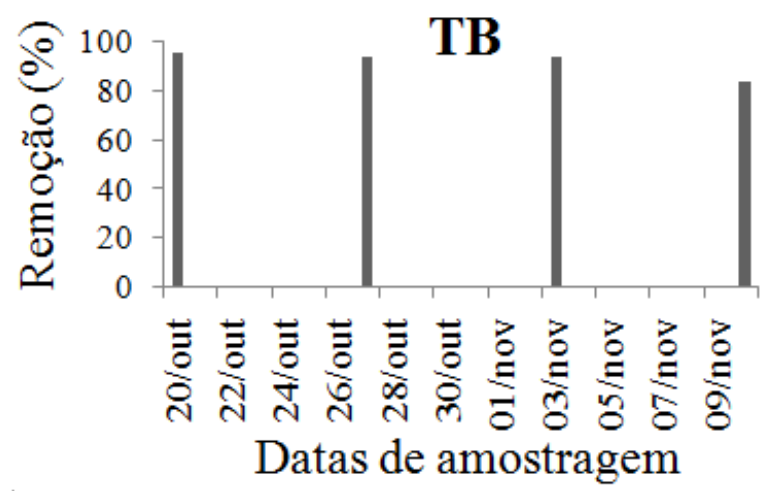

Figura 2. Remoção de turbidez (TB) do esgoto doméstico no sistema de tratamento, ao longo do período experimental.

Os valores de Demanda Química de Oxigênio (DQO) do efluente no reator solar (ponto 4) apresentaram variações de 121,15 a 160,20 $\mathrm{mg} \mathrm{L}^{-1}$, nos quatro dias de amostragem. Constatou-se, ao longo do período experimental, que a DQO atendeu ao limite de $200 \mathrm{mg} \mathrm{L}^{-1}$ para lançamento direto de efluente tratado em corpo hídrico receptor (Ceará, 2002). As remoções de DQO, ao longo do período experimental, foram de 64 a $74 \%$.

Comparando os valores de Demanda Bioquímica de Oxigênio (DBO) dos efluentes coletados nos pontos 1 e 4, nos quatro dias de amostragem, verificou-se que as remoções desta característica oscilaram de 57 a $65 \%$. No entanto, os valores de DBO no ponto 4, obtidos ao longo do período experimental, foram inferiores ao limite máximo de $120 \mathrm{mg} \mathrm{L}^{-1}$ estabelecido pela Resolução CONAMA n. ${ }^{\circ} 430$ para lançamento de esgotos domésticos tratado em corpos hídricos (Brasil, 2011). Este limite somente poderá ser ultrapassado no caso de efluente de sistema de tratamento com eficiência de remoção mínima de $60 \%$ de DBO, ou mediante estudo de autodepuração do corpo hídrico que comprove atendimento às metas do enquadramento do corpo receptor, conforme especificado na Resolução CONAMA n ${ }^{\circ} 357$ (Brasil, 2005). A Figura 3 mostra essa remoção encontrada. 


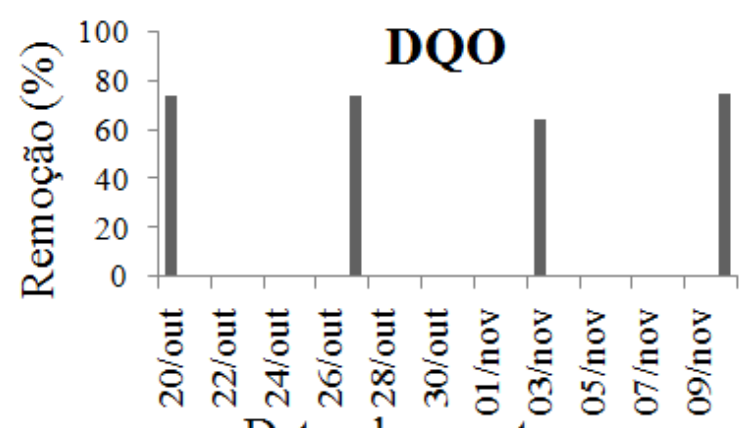

Datas de amostragem

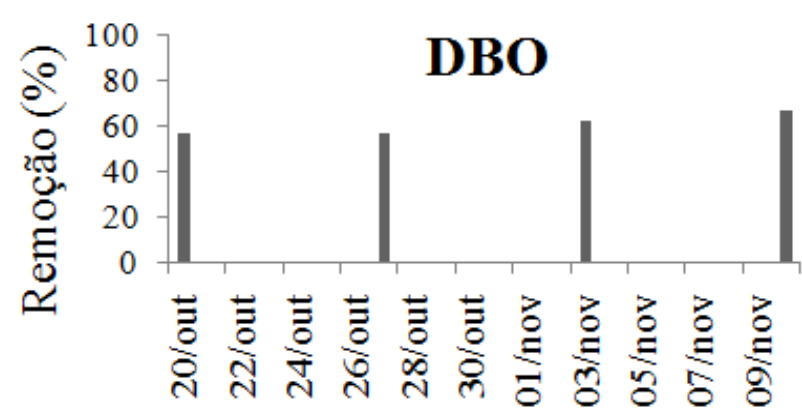

Datas de amostragem

Figura 3. Remoção da Demanda Química de Oxigênio (DQO) e Demanda Bioquímica de Oxigênio (DBO) do esgoto doméstico no sistema de tratamento, ao longo do período experimental.

Constatou-se que os valores de sólidos suspensos do efluente do reator solar (ponto 4) oscilaram de 6 a $68 \mathrm{mg} \mathrm{L}^{-1}$. Realizando comparações entre os valores de sólidos suspensos para os pontos 1 e 4 constataram-se remoções de 89 a $99 \%$. De acordo com a Portaria ${ }^{\circ}{ }^{0} 154$ do Estado do Ceará (Ceará, 2002), os resultados de sólidos suspensos foram inferiores ao limite de $50 \mathrm{mg} \mathrm{L}^{-1}$ estabelecido para lançamento de efluentes tratados em corpo hídrico, exceto no dia 20 de outubro de 2010.

Os valores de sólidos totais apresentaram variações de 366 a $610 \mathrm{mg} \mathrm{L}^{-1}$ para os efluentes coletados no reator solar (ponto 4). Notaram-se, também, remoções de sólidos totais variando de 35 a 61\%, ao longo do período experimental, conforme apresentado na Figura 4.
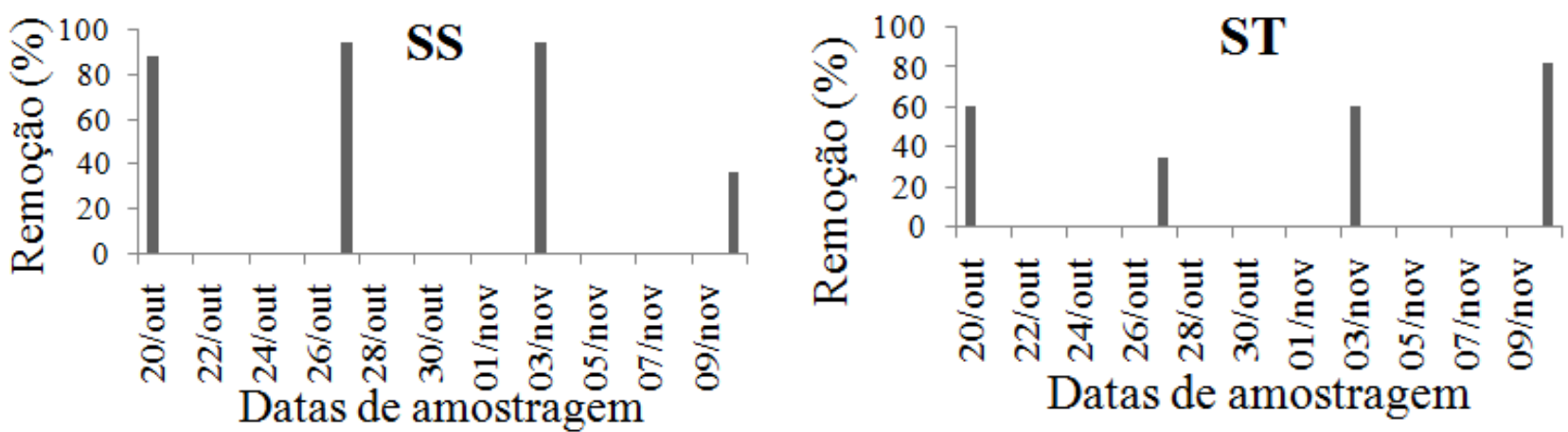

Figura 4. Remoção dos sólidos suspensos (SS) e sólidos totais (ST) do esgoto doméstico no sistema de tratamento, ao longo do período experimental.

As concentrações de fósforo nos efluentes coletados no ponto 4 oscilaram de 6,90 a $16,29 \mathrm{mg} \mathrm{L}^{-1}$. Verificou-se que as remoções de fósforo variaram de 41 a $60 \%$, ao longo do período experimental, como apresentado na Figura 5.

Os valores de óleos e graxas (substâncias solúveis em hexano) do efluente do reator solar (ponto 4) apresentaram variação de 1,20 a $6,90 \mathrm{mg} \mathrm{L}^{-1}$. Os resultados obtidos em todo período experimental foram inferiores ao limite de $100 \mathrm{mg} \mathrm{L}^{-1}$ estabelecido pela Resolução CONAMA n. ${ }^{\circ} 430$ (Brasil, 2011) para lançamento de esgotos domésticos tratados em corpo hídrico receptor. As remoções de óleos e graxas variaram de 95 a 99,7\% ao longo do período experimental (Figura 5). 
REINALDO, G. P. B.; BATISTA, R. O.; SILVA, P. C. M.; LEMOS FILHO, L. C. A.; FERREIRA NETO, M. SANTOS, D. B. Desempenho de sistema decanto-digestor com filtro biológico seguido por alagado construído e reator solar no tratamento de esgoto doméstico. Ambi-Agua, Taubaté, v. 7, n. 2, p. 62-74, 2012. (http://dx.doi.org/10.4136/ambi-agua.723)

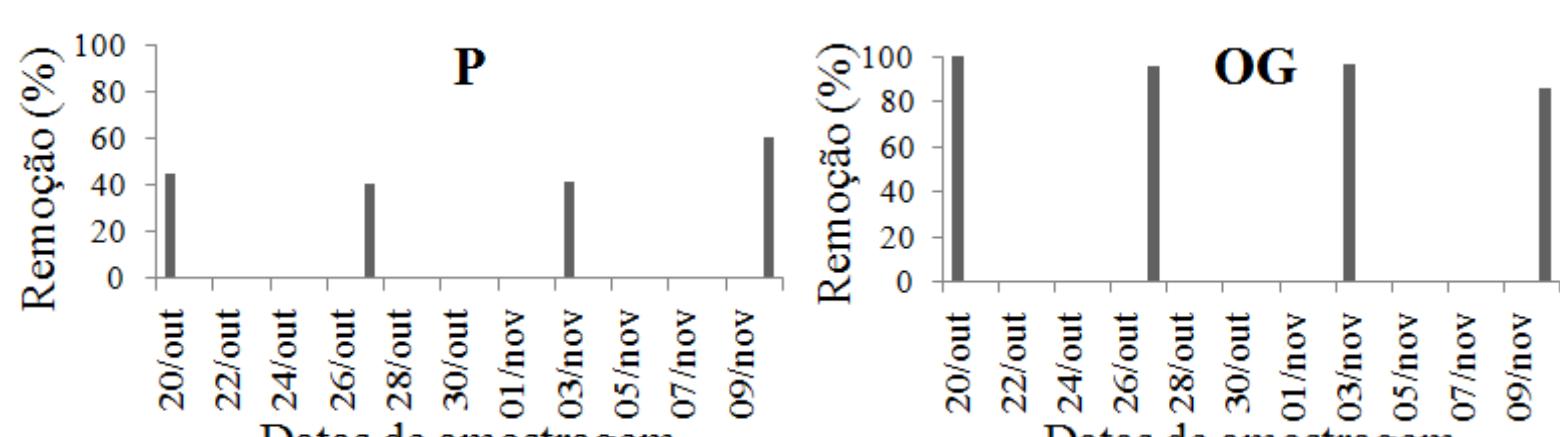

Datas de amostragem

Datas de amostragem

Figura 5. Remoção de fósforo total (P) e óleos e graxas (OG) do esgoto doméstico no sistema de tratamento, ao longo do período experimental.

Em relação às características microbiológicas, observou-se que houve redução no nível populacional de coliformes totais e termotolerantes quando se estabelece comparação entre os pontos 1 e 4 , durante o período experimental.

As remoções de coliformes totais e termotolerantes oscilaram de 99,36 a 99,99 e de 99,91 a 99,99\%, respectivamente. De acordo com os limites estabelecidos pela Portaria $n .{ }^{\circ}$ 154 do Estado do Ceará (Ceará, 2002), o efluente atende as recomendações para irrigação de culturas não consumidas cruas, onde o nível populacional de coliforme termotolerantes deva ser inferior a $5000 \mathrm{NMP} 100 \mathrm{~mL}^{-1}$ (Número Mais Provável por $100 \mathrm{~mL}$ ).

Os níveis de remoção de coliformes totais e termotolerantes foram semelhantes aos obtidos por Moura et al. (2011) com o uso de reatores solares para a desinfecção de esgoto doméstico de filtro anaeróbio. Moura et al. (2011) verificaram que um tempo de exposição de 12 horas permitiu remoções de até 99,99 e 99,99\% na população de coliforme total e coliforme fecal, respectivamente como mostrado na Figura 6.

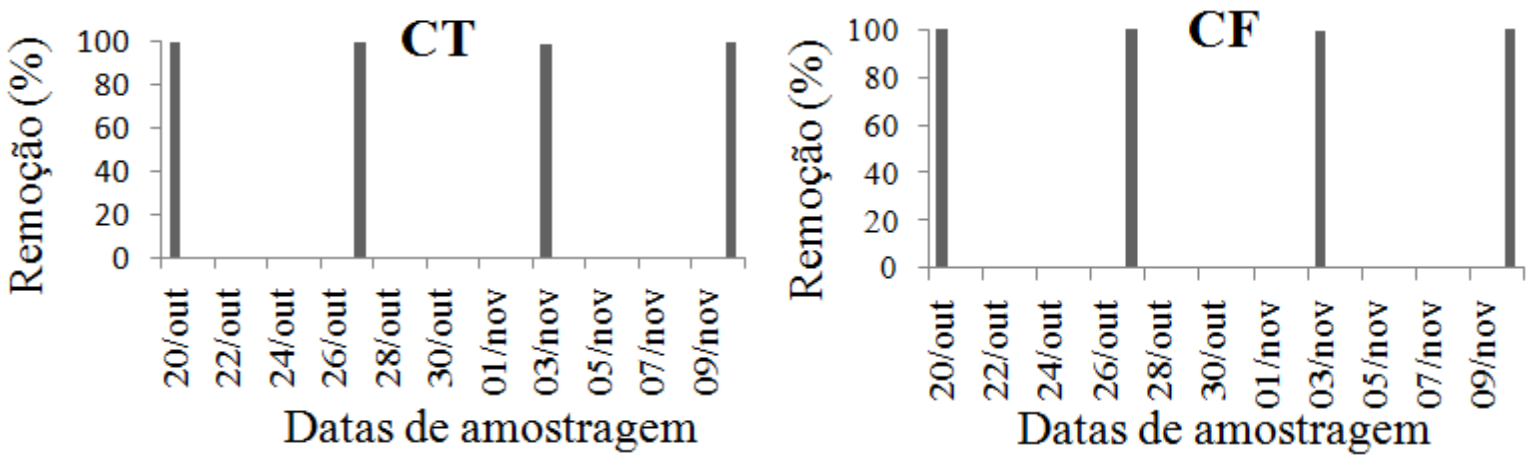

Figura 6. Remoção de coliformes totais (CT) e coliformes fecais (CF) do esgoto doméstico no sistema de tratamento, ao longo do período experimental.

Estão apresentados na Tabela 3 os valores médios e o resumo da análise estatística das características físicas, químicas e microbiológicas do esgoto doméstico nas etapas de tratamento referentes aos pontos 1, 2, 3 e 4 na fase inicial de desenvolvimento do capim elefante. 
REINALDO, G. P. B.; BATISTA, R. O.; SILVA, P. C. M.; LEMOS FILHO, L. C. A.; FERREIRA NETO, M. SANTOS, D. B. Desempenho de sistema decanto-digestor com filtro biológico seguido por alagado construído e reator solar no tratamento de esgoto doméstico. Ambi-Agua, Taubaté, v. 7, n. 2, p. 62-74, 2012. (http://dx.doi.org/10.4136/ambi-agua.723)

Tabela 3. Valores médios e o resumo dos testes estatísticos das características físicas e químicas do esgoto doméstico nos pontos de amostragem 1, 2, 3 e 4 dos protótipos de tratamento de esgoto doméstico.

\begin{tabular}{|c|c|c|c|c|c|}
\hline \multirow{2}{*}{ Característica } & \multirow{2}{*}{$\mathbf{F}$} & \multicolumn{4}{|c|}{ Amostragem } \\
\hline & & Ponto 1 & Ponto 2 & Ponto 3 & Ponto 4 \\
\hline $\mathrm{pH}$ & $3,99^{\text {ns }}$ & 6,65 & 6,65 & 6,61 & 6,17 \\
\hline Condutividade elétrica $\left(\mathrm{dS} \mathrm{m}^{-1}\right)$ & $0,09^{\mathrm{ns}}$ & 1,26 & 1,23 & 1,2 & 1,19 \\
\hline Turbidez (UNT) & $6,22 *$ & $576,50 \mathrm{a}$ & $116,28 b$ & $37,10 \mathrm{~b}$ & $33,47 b$ \\
\hline Coliformes totais (NMP $100 \mathrm{~mL}$ ) & $2,39^{\mathrm{ns}}$ & $6,8 \times 10^{7}$ & & & $4,7 \times 10^{5}$ \\
\hline Coliformes termotolerantes (NMP $100 \mathrm{~mL}$ ) & $50,75^{*}$ & $1,1 \times 10^{6} \mathrm{a}$ & & & $2,8 \times 10^{2} b$ \\
\hline Demanda Química de Oxigênio (DQO) & $150,51 *$ & $459,19 a$ & & & $138,54 b$ \\
\hline Demanda Bioquímica de Oxigênio $\left(\mathrm{DBO}_{5}\right)$ & $214,39 *$ & $181,56 a$ & & & $72,15 b$ \\
\hline Sólidos totais $\left(\mathrm{mg} \mathrm{L}^{-1}\right)$ & $65,88 *$ & $922,50 \mathrm{a}$ & $735,75 \mathrm{a}$ & $487,75 b$ & $452,00 \mathrm{~b}$ \\
\hline Sólidos suspensos $\left(\mathrm{mg} \mathrm{L}^{-1}\right)$ & $41,81^{*}$ & $423,00 \mathrm{a}$ & $261,00 \mathrm{a}$ & $30,75 b$ & $25,00 \mathrm{~b}$ \\
\hline Fósforo (mg L $\left.{ }^{-1}\right)$ & $12,26^{*}$ & $24,13 a$ & & & $13,18 b$ \\
\hline Nitrogênio total $\left(\mathrm{mg} \mathrm{L}^{-1}\right)$ & $1,22^{\mathrm{ns}}$ & 55,94 & & & 52,98 \\
\hline Óleos e graxas $\left(\mathrm{mg} \mathrm{L}^{-1}\right)$ & $16,91 *$ & $208,28 \mathrm{a}$ & & & $3,33 b$ \\
\hline Nitrato $\left(\mathrm{mg} \mathrm{L}^{-1}\right)$ & $2,56^{\mathrm{ns}}$ & 13,54 & & & 26,83 \\
\hline
\end{tabular}

Nota: Ponto 1: efluente coletado na entrada do decanto-digestor; Ponto 2: efluente coletado na saída do decanto-digestor; Ponto 3: efluente coletado à jusante do sistema alagado construído; e Ponto 4: efluente coletado no reator solar. * F significativo a $5 \%$ de probabilidade. ns $\mathrm{F}$ não-significativo a $5 \%$ de probabilidade. Médias seguidas de pelo menos uma mesma letra nas linhas não diferem entre si, a $5 \%$ de probabilidade, pelo teste de Tukey.

Pela análise de variância, verificou-se que as características $\mathrm{pH}$, condutividade elétrica, coliformes totais nitrogênio total e nitrato não foram significativas a 5\% de probabilidade pelo teste F. Enquanto, as características turbidez, coliformes termotolerantes, Demanda Química de Oxigênio, Demanda Bioquímica de Oxigênio, sólidos totais, sólidos suspensos, fósforo e óleos e graxas foram significativas a $5 \%$ de probabilidade pelo teste $\mathrm{F}$, o que permite a utilização do teste de Tukey para comparação das médias (Tabela 3).

Estabelecendo comparação entre os pontos 1 e 4, notou-se que as características turbidez, coliformes termotolerantes, Demanda Química de Oxigênio, Demanda Bioquímica de Oxigênio, sólidos totais, sólidos suspensos, fósforo e óleos e graxas diferem estatisticamente entre si à 5\% de probabilidade pelo teste de Tukey. Significa afirmar que o tratamento foi eficiente na remoção das características analisadas, o que tornar esta técnica valida e eficaz para o tratamento de esgoto domestico nestas condições ambientais.

$\mathrm{Na}$ Figura 7 está apresentado o indicador visual do nível de tratamento obtido no sistema implantado na Projeto de Assentamento Milagres, em Apodi-RN. Notou-se, nesta figura, que o sistema proporcionou ótima remoção de turbidez, sólidos e carga orgânica com tratamento preliminar/primário no decanto digestor e filtros anaeróbios, tratamento secundário/terciário no sistema alagado construído e tratamento terciário no reator solar. 


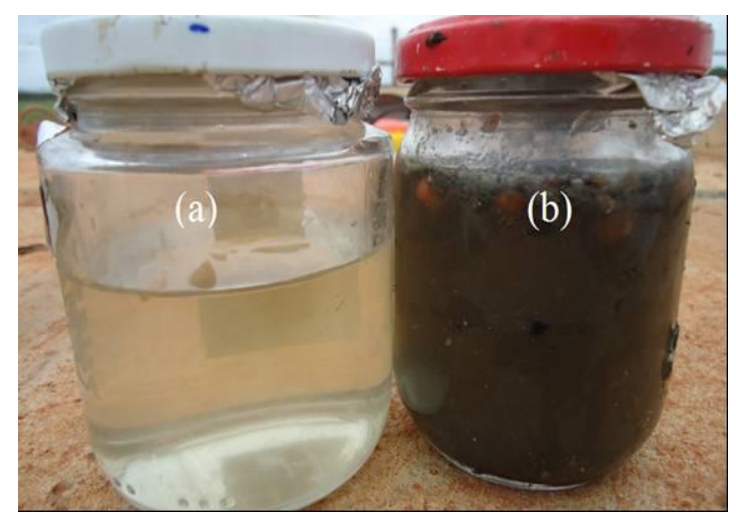

Figura 7. Indicador visual do nível de tratamento obtido na mini-estação. Efluente tratado (a) e efluente sem tratamento (b).

\section{CONCLUSÃO}

Diante dos resultados, conclui-se que: houve remoção significativa de turbidez, Demanda Bioquímica de Oxigênio, Demanda Química de Oxigênio, sólidos suspensos, fósforo nitrogênio total e óleos e graxas com o uso conjunto de decanto-digestor, sistema alagado construído e reator solar; os valores de óleos e graxas e Demanda Bioquímica de Oxigênio atendem as recomendações nacionais para lançamento de esgoto doméstico tratado em corpo hídrico; com um valor médio de radiação solar de $28,73 \mathrm{MJ} \mathrm{m}^{-2} \mathrm{~d}^{-1}$ com uso de uma lâmina de 0,10 m de efluente e tempo de exposição solar 12 horas em Apodi-RN permitiu remoção de até $99,99 \%$ dos coliformes termotolerantes; e o efluente tratado apresenta um padrão microbiológico que atende as diretrizes estaduais para irrigação de cultivos agrícolas não consumidos crus.

\section{AGRADECIMENTOS}

Agradecemos à FINEP e à Universidade Federal Rural do Semi-Árido pelo apoio financeiro.

\section{REFERÊNCIAS}

AMERICAN PUBLIC HEALTH ASSOCIATION - APHA. Standard methods for the examination of water and wastewater. 21th ed. Washington, DC,.2005.

ASSOCIAÇÃO BRASILEIRA DE NORMAS TÉCNICAS - ABNT. NBR 7229:1993: projeto, construção e operação de sistemas de tanques sépticos. Rio de Janeiro, 1993. $15 \mathrm{p}$.

ASSOCIAÇÃO BRASILEIRA DE NORMAS TÉCNICAS- ABNT. NBR 7229:1982: construção e instalação de fossas sépticas e disposição dos efluentes finais. Rio de Janeiro, 1982. 37p.

BATISTA, R. O.; SARTORI, M. A.; SOARES, A. A.; MOURA, F. N.; COSTA PAIVA, M. R. F. Potencial da remoção de poluentes bioquímicos em biofiltros operando com esgoto doméstico. Revista Ambiente \& Água, v. 6, n. 3, p. 152-164, 2011. http://dx.doi.org/10.4136/ambi-agua.625 
REINALDO, G. P. B.; BATISTA, R. O.; SILVA, P. C. M.; LEMOS FILHO, L. C. A.; FERREIRA NETO, M. SANTOS, D. B. Desempenho de sistema decanto-digestor com filtro biológico seguido por alagado construído e reator solar no tratamento de esgoto doméstico. Ambi-Agua, Taubaté, v. 7, n. 2, p. 62-74, 2012. (http://dx.doi.org/10.4136/ambi-agua.723)

BRASIL. Conselho Nacional do Meio Ambiente. Resolução no 430, de 13 de maio de 2011. Dispõe sobre as condições e padrões de lançamento de efluentes, complementa e altera a Resolução no 357, de 17 de março de 2005. Disponível em: <http://www.mma.gov.br/port/conama/res/res05/res35705.pdf $>$. Acesso em: 03 jun. 2012.

BRASIL. Conselho Nacional do Meio Ambiente. Resolução no 357, de 17 de março de 2005. Dispõe sobre a classificação dos corpos de água e diretrizes ambientais para o seu enquadramento, bem como estabelece as condições e padrões de lançamento de efluentes. Disponível em: <http://www.mma.gov.br/port/conama/res/res05/res35705. pdf>.Acesso em: 31 mai. 2012.

BRASIL, M. S.; MATOS, A. T.; SOARES, A. A.; FERREIRA, P. A. Qualidade do efluente de sistemas alagados construídos, utilizados no tratamento de esgoto doméstico. Revista Brasileira de Engenharia Agrícola e Ambiental, v. 9, p. 133-137, 2005. Suplemento.

CEARÁ. Portaria $\mathbf{n}^{\circ} \mathbf{1 5 4}$, de 22 de julho de 2002. Dispõe sobre padrões e condições para lançamento de efluentes líquidos gerados por fontes poluidoras. Disponível em: $<$ http://antigo.semace.ce.gov.br/integracao/biblioteca/legislacao/conteudo_legislacao.as p?cd=95>. Acesso em: 25 mai. 2012.

INTITUTO BRASILEIRO DE GEOGRAFIA E ESTATÍCTICA - IBGE. Pesquisa nacional de saneamento básico 2008. Rio de Janeiro, 2010. 219p.

MATOS, A. T. Disposição de águas residuárias no solo. Viçosa, MG: AEAGRI, 2007. 140 p. (Caderno didático, n. 38).

MOURA, F. N.; BATISTA, R. O.; SIlVA, J. B. A.; FEITOSA, A. P.; COSTA, M. S. Desempenho de sistema para tratamento e aproveitamento de esgoto doméstico em áreas rurais do semiárido brasileiro. Engenharia Ambiental, v. 8, n. 3, p. 264-276, 2011.

OLIVEIRA, D. Q. L.; CARVALHO, K. T. G.; BASTOS, A. R. R.; OLIVEIRA, L. C. A.; MARQUES, J. J. G. S. M.; NASCIMENTO, R. S. M. P. Utilização de resíduos da indústria de couro como fonte nitrogenada para o capim-elefante. Revista Brasileira de Ciência do Solo, v. 32, n. 1, 417-424, 2008. http://dx.doi.org/10.1590/S010006832008000100039

PROCHASKA, C. A.; ZOUBOUSLIS, A. I. Treatment performance variation at different depths within vertical subsurface-flow experimental wetlands fed with simulated domestic sewage. Desalination, Thessaloniki, v. 237, n. 1-3, p. 367-377, 2008. http://dx.doi.org/10.1016/j.desal.2008.01.028

RIBAS, T. B. C.; FORTES NETO, P. Disposição no solo de efluentes de esgoto tratado visando à redução de coliformes termotolerantes. Revista Ambiente \& Água, v. 3, n. 3, p. 81-94, 2008. http://dx.doi.org/10.4136/ambi-agua.63

SÁNCHEZ-ROMÁN, R.M.; SOARES, A.A.; MATOS, A.T.; SEDIYAMA, G.C.; SOUZA, O.; MOUNTEER, H.A. Domestic wastewater disinfection using solar radiativa for agricultural reuse. Transactions of the ASABE, v.50, n.1, p.65-71, 2007.

UNITED NATIONS DEVELOPMENT PROGRAMME - UNDP. Human development report 2006: power, poverty and the global water crisis. New York, 2006. 440p. 